\title{
Elucidating the identity and behavior of spermatogenic stem cells in the mouse testis
}

\author{
Shosei Yoshida ${ }^{1,2}$ \\ ${ }^{1}$ Division of Germ Cell Biology, National Institute for Basic Biology, 5-1 Higashiyama, Myodaiji, Okazaki, \\ Aichi 444-8787, Japan and ${ }^{2}$ Department of Basic Biology, SOKENDAl, 5-1 Higashiyama, Myodaiji, Okazaki, \\ Aichi 444-8787, Japan \\ Correspondence should be addressed to S Yoshida at Division of Germ Cell Biology, National Institute for Basic Biology; \\ Email: shosei@nibb.ac.jp
}

\begin{abstract}
Spermatogenesis in mice and other mammalians is supported by a robust stem cell system. Stem cells maintain themselves and continue to produce progeny that will differentiate into sperm over a long period. The pioneering studies conducted from the 1950 s to the 1970 , which were based largely on extensive morphological analyses, have established the fundamentals of mammalian spermatogenesis and its stem cells. The prevailing so-called $A_{\text {single }}\left(A_{s}\right)$ model, which was originally established in 1971 , proposes that singly isolated $A_{s}$ spermatogonia are in fact the stem cells. In 1994, the first functional stem cell assay was established based on the formation of repopulating colonies after transplantation in germ cell-depleted host testes, which substantially accelerated the understanding of spermatogenic stem cells. However, because testicular tissues are dissociated into single-cell suspension before transplantation, it was impossible to evaluate the $A_{s}$ and other classical models solely by this technique. From 2007 onwards, functional assessment of stem cells without destroying the tissue architecture has become feasible by means of pulse-labeling and live-imaging strategies. Results obtained from these experiments have been challenging the classical thought of stem cells, in which stem cells are a limited number of specialized cells undergoing asymmetric division to produce one self-renewing and one differentiating daughter cells. In contrast, the emerging data suggest that an extended and heterogeneous population of cells exhibiting different degrees of self-renewing and differentiating probabilities forms a reversible, flexible, and stochastic stem cell system as a population. These features may lead to establishment of a more universal principle on stem cells that is shared by other systems.
\end{abstract}

Reproduction (2012) $\mathbf{1 4 4} 293-302$

\section{Morphological basics of mouse spermatogenesis and its stem cells}

Mouse spermatogenesis occurs in seminiferous tubule of the testis. Fig. 1A and B illustrate a simplified architecture of the seminiferous tubules (Russell et al. 1990, Yoshida 2010). The anatomical framework of the tubules consists of the peripheral basement membrane and two types of somatic cells, i.e. Sertoli and peritubular cells. Sertoli cells comprise an epithelium inside the basement membrane, whose tight junctions provide an anatomical basis of blood-testis barrier, while peritubular cells cover the outside of the basement membrane. All the stages of germ cells from stem cells to spermatozoa are located between and nourished by Sertoli cells (Fig. 1B and C). Spermatogonia, which are defined as mitotic stages of spermatogenic cells including stem and differentiating cell types, occupy the basal compartment between basement membrane and the Sertoli cells' tight junction.
Characteristically, spermatogonia form syncytia between their mitotic sisters due to an incomplete cytokinesis, which causes the synchronization of the subsequent divisions. As a result, spermatogonia are typically found as single isolated cells (designated as $\left.A_{\text {single }}\left(A_{s}\right)\right)$ or syncytia of $2^{n}(2,4,8,16$, etc.) cells. The syncytia continue to extend along with subsequent course of differentiation. Spermatogonia of mouse and other rodent are often classified into two: the so-called 'undifferentiated' and 'differentiating' spermatogonia. 'Undifferentiated' spermatogonia (sometimes designated as $\left.A_{\text {undiff }}\right)$ consist of $A_{s}, A_{\text {paired }}\left(A_{p r}\right.$, syncytia of two cells), and $A_{\text {aligned }}\left(A_{a l}\right.$, syncytia of $4,8,16$, and occasionally 32 cells). 'Differentiating' spermatogonia are derived from 'undifferentiated' spermatogonia and proceed highly organized differentiation process and include $A_{1}, A_{2}, A_{3}$, $A_{4}$, In, and $B$ spermatogonia, showing synchronous division accompanying the extension of the syncytia. The term 'undifferentiated' may be misleading because formation and extension of spermatogonial syncytia are 




Figure 1 Anatomy of the seminiferous tubules and the process of spermatogenesis. (A) Architecture of seminiferous tubules shown by actual tissue image and (B) schematic representation. (C) Scheme of the spermatogenic cell types observed in the mouse testis. All the spermatogonia, including stem cells, occupy the basal compartment of the tubule, while subsequent differentiating cells are stratified to the lumen. See text for the details. Modified from Yoshida S 2010 Stem cells in mammalian spermatogenesis. Development, Growth \& Differentiation 52 311-317. Reproduced with permisson from John Wiley and Sons. Copyright 2010 Japanese Society of Developmental Biologists.

considered as an important signature of differentiation (de Rooij \& Russell 2000). However, this term will be used in this review not only because no other terms correctly indicate this collective entity but also because this population seems to retain potential of self-renewing and formation of syncytia does not indicate irreversible commitment for differentiation (discussed later). When spermatogonia enter meiosis, large syncytia of germ cells - now designated as spermatocytes - translocate across the tight junction into adluminal compartment. After meiosis, haploid round and then elongating spermatids form and mature into spermatozoa as the cells move towards the lumen. Clearly, stem cells comprise a subpopulation of spermatogonia in the basal compartment, but elucidation of their identity and behaviors has long been a big challenge.

\section{Spermatogenic stem cell models}

Several models have been proposed with respect to the identity and behavior of stem cells, essentially on the basis of intensive morphological investigations of fixed specimens (for review Russell et al. (1990), Meistrich \& van Beek (1993) and de Rooij \& Russell (2000)). Among them the so-called ' $A_{s}$ model' became prevailing, which proposed that singly isolated $A_{s}$ spermatogonium is the only cell type that act as stem cells (Fig. 2A). Whereas, interconnected syncytia of $A_{p r}$ and $A_{a l}$, as well as more matured differentiating spermatogonia, are considered no longer capable of self-renewal and irreversibly committed for differentiation (Huckins 1971, Oakberg 1971). A second model hypothesized that some spermatogonial syncytia are fragmented and replenish the stem cell pool, based on the presence of syncytia with the cell numbers of other than $2^{n}$ at a higher frequency after irradiation (Erickson 1978).

However, it was theoretically impossible to obtain a final conclusion solely based on the morphology of spermatogonia. First, precise judgment of spermatogonial interconnection in whole-mounted seminiferous tubule specimen (Clermont \& Bustos-Obregon 1968) is difficult because intercellular bridges are not always visible under microscope, and identification of syncytia was practically based on the distance between nuclei with similar appearance that reflect their cell cycle phase (de Rooij \& Russell 2000). More fundamentally, what one needs to know more is the behavior of spermatogonia over time (i.e. proliferation, differentiation, death, etc.) in order to fully understand the stem cell system.

In the field of mammalian spermatogenesis, the syncytia of spermatogonia have often been called a 'clone', which by definition indicates a group of cells derived from a single ancestor cell. This term is appropriate if we rely on the $A_{s}$ model. However, this may be confusing if one considers fragmentation of a syncytium, which gives rise to multiple syncytia that belong to a single 'clone'. Indeed, such fragmentations have recently been observed by live imaging (Nakagawa et al. 2010). Our recent literature used 'cysts', which are widely used for germline of Drosophila and sometimes for other animals including mammalians (Nakagawa et al. 2010). However, in Drosophila, syncytia of spermatogonia are encapsulated by somatic cells, while 'cysts' are used for this entire structure of spermatogonia and the surrounding somatic cells (called cyst cells). Given that mammalian spermatogonia are not encapsulated, I realize that 'cyst' may also be confusing. Therefore, 'syncytia' or 'spermatogonial syncytia' will 
A

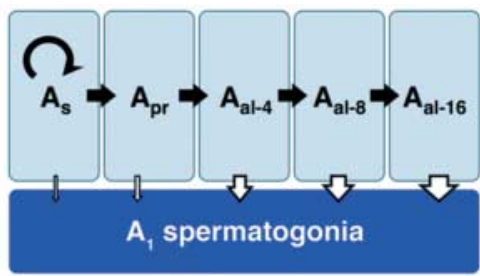

B

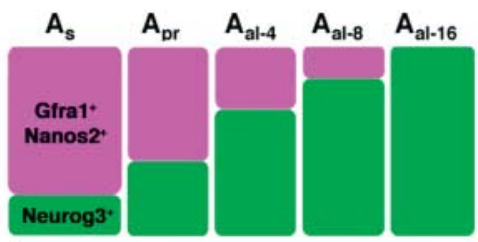

Kit $A_{1}$ spermatogonia

C

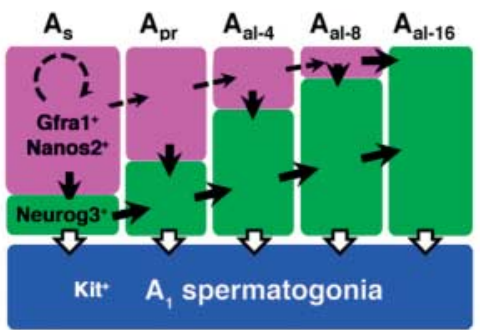

D



Figure 2 Schematic representations of undifferentiated spermatogonia subsets and their functional link. (A) The $A_{s}$ model. This is entirely based on the anatomical classification or number of interconnected cells within individual syncytia, proposing that $A_{s}$ is the only cell type that can act as stem cells while interconnected cells are irreversibly committed for differentiation. (B) A simplified diagram for subpopulations based on gene expression analyses. Syncytia of the same morphological entity are classified by their gene expression as shown (C) Flows of a bulk of cells between indicated subpopulations. Processes shown by solid arrows are directly observed by live imaging, while dotted arrows indicated imaginary processes. (D) Cell flow between $\mathrm{A}_{\text {undiff }}$ subpopulations under steady state, which include reversion shown by yellow arrows. Modified from Nakagawa T, Sharma M, Nabeshima Y, Braun RE \& Yoshida S 2010 Functional hierarchy and reversibility within the murine spermatogenic stem cell compartment. Science 328 62-67. Reproduced with permission from The American Association for the Advancement of Science. Copyright 2010 The American Association for the Advancement of Science.

be used in this review. Of note, the spermatogonial syncytia comprised mitotic sisters and cousins as a result of incomplete divisions, which is contrary to other examples of multinucleated syncytia formed by cell fusion (skeletal muscles, syncytial trophoblasts, etc.).

\section{Heterogeneous composition of 'undifferentiated' spermatogonia in their gene expression}

'Undifferentiated' spermatogonia, which include $A_{s}, A_{p r}$ and $A_{a l}$, are anatomically heterogeneous, with regards to the number of cells within individual syncytia (Fig. 2A). However, they share a very similar characteristic nuclear morphology that is distinct from that of differentiating spermatogonia, i.e. minimal heterochromatin condensation (Chiarini-Garcia \& Russell 2001 , 2002), suggesting that this entity of cells $\left(A_{s}, A_{p r}\right.$ and $A_{a l}$ ) shares some important features. Indeed, undifferentiated spermatogonia are characterized by unique gene expression, i.e. $P l z f^{\mathrm{pos}} / E$-Cadherin ${ }^{\mathrm{pos}} / \mathrm{Kit}^{\text {neg }}$. This is distinct from 'differentiating' spermatogonia, which are $\mathrm{Pl} / \mathrm{f}^{\mathrm{neg}} / \mathrm{E}_{\text {-Cadherin }}{ }^{\mathrm{neg}} / \mathrm{Kit}^{\mathrm{pos}}$ (Schrans-Stassen et al. 1999, Buaas et al. 2004, Costoya et al. 2004, Tokuda et al. 2007). However, expression of some genes such as Gfra1 (also known as GFR 1 ), Nanos2, and Neurog3 (also known as Ngn3 or Neurogenin3) exhibits internal heterogeneity in undifferentiated spermatogonia population (Yoshida et al. 2004, Hofmann et al. 2005b, Tokuda et al. 2007, Suzuki et al. 2009, Zheng et al. 2009, Nakagawa et al. 2010, Yoshida 2010), as shown in a simplified manner in Fig. 2B. The Gfra $1^{\text {pos }} /$ Nanos $2^{\text {pos }}$ ${\text { (Neurog } 3^{\text {neg }} / \text { Nanos } 3^{\text {low }} / \text { E-cadherin }}^{\text {pos }} / \mathrm{Pl}_{2} f^{\text {pos }} /$ Kit $^{\text {neg }}$ ) population contains a majority of the $A_{s}$ and $A_{p r}$ spermatogonia, while the Neurog $3^{\text {pos }}$ population (Gfra $1^{\text {neg/Nanos } 2^{\text {neg }} / \text { Nanos } 3{ }^{\text {high }} / \text { E-Cadherin }}{ }^{\text {pos}} / P l z f^{\text {pos}} /$ $\left.K_{i t}{ }^{\text {neg) }}\right)$ largely corresponds to the $A_{a l}$ spermatogonia. Interestingly, this heterogeneity is different from morphological heterogeneity, namely the number of cells within a syncytium. Importantly, $A_{s}$ spermatogonia population, which has been generally considered to be uniformly the stem cells, was shown to be a heterogeneous entity: while many of them are Gfra $1^{\text {pos }} / \mathrm{Nanos} 2^{\text {pos }} /$ Neurog $3^{\text {neg }}$, some are Gfra $1^{\text {neg }} /$ Nanos $2^{\text {neg }} /$ Neurog $3^{\text {pos }}$.

It is also likely, however, that the above-mentioned heterogeneity of gene expression is not the only heterogeneity in the $A_{\text {undiff }}$ population. For example, interestingly, $I d 4$ is reported to be expressed only in $A_{s}$ spermatogonia (Oatley et al. 2011). Accumulation of gene expression pattern would reveal more detailed heterogeneity in this population.

\section{Transplantation: functional assessment of spermato- genic stem cells}

Experiments such as artificial cryptorchid testes and testes of vitamin A-deficient animals (Nishimune et al. 1978, van Pelt \& de Rooij 1990, Hogarth \& Griswold 2010) had functionally indicated that 'undifferentiated' spermatogonia population is responsible for the stem cell activity: in these situations, spermatogenesis arrests and only undifferentiated spermatogonia were observed, which is enough to reestablish complete 
spermatogenesis after testes are relocated back into scrotum or dietary vitamin A is restored.

Then, post-transplantation repopulation of spermatogenesis established by Brinster and colleagues opened the door for the functional and quantitative assay of spermatogenic stem cells (Brinster \& Avarbock 1994, Brinster \& Zimmermann 1994). Like hematopoiesis, selfrenewing, and differentiating, abilities of a single stem cell became assayable by direct measurement of the post-transplantation colony formation. Using this experimental system, it was rediscovered that a vast majority of the stem cell activity resides in Kit ${ }^{\text {neg }}$ 'undifferentiated' spermatogonia (Shinohara et al. 2000, Ohbo et al. 2003). Sorted fractions of $\mathrm{Kit}^{\mathrm{pos}}$ 'differentiating' spermatogonia $\left(A_{1}\right.$ to $A_{4}$, In and $\left.B\right)$ also showed some low activity of post-transplantation colony formation (Shinohara et al. 2000, Ohbo et al. 2003, Barroca et al. 2009). The origin of this activity is interesting, while the purity of the fractions warrants careful evaluation.

In undifferentiated spermatogonia, transplantable stem cell activity was detected both in Gfra ${ }^{\text {pos }}$ and in Gfra $1^{\text {neg }}$ (likely to be Neurog3 ${ }^{\text {pos }}$ ) fractions (Hofmann et al. 2005a, Nakagawa et al. 2007, Grisanti et al. 2009). It is noteworthy that in vitro culture that retains the stem cell activity, another big breakthrough in this field, has been developed taking advantage of this transplantationbased stem cell assay (Kanatsu-Shinohara et al. 2003, Kubota et al. 2004).

On transplantation, the donor testes are dissociated into single cell suspensions, making it impossible to link the morphological classification of spermatogonia (i.e. $A_{s}, A_{p r}$ or $A_{a l}$ ) to their stem cell activity. In addition, the host germ cells need to be depleted before transplantation. Therefore, while transplantation reveals the ability of self-renewal, it may not reflect the stem cell functionality in the steady-state spermatogenesis that undergoes in undisturbed testes. Indeed, the same donor cells give rise to much larger number of colonies when transplanted into young hosts, indicating that detection of stem cell potential is context-dependent (Shinohara et al. 2001). Therefore, while it is no doubt that transplantation and in vitro cultures have provided important implications for the stem cell behavior in vivo, methods that enable to analyze the stem cell function under normal tissue architecture have also been warranted.

\section{Pulse chase and live imaging: stem cell analysis in undisturbed testes}

In principle, two types of experiments are capable of analyzing particular cells' behavior in undisturbed tissues or organs. First is the 'pulse-chase' experiment, in which irreversible and inheritable label is introduced to the cells of interest followed by detection of labeled cells after a certain period of time (Fig. 3). If stem cells are pulse labeled, the label is expected to persist in both the stem and the differentiating descendants for prolonged period (Fig. 3B). On the other hand, if transit amplifying cells are induced, the label will be observed in differentiating progeny only transiently (Fig. 3C). Several kinds of genetic labeling technology have been developed mainly in mice and fruitflies (Fox et al. 2008, Buckingham \& Meilhac 2011). In mice, tamoxifeninducible Cre recombinase-LoxP system is the most widely used system, which recombines the reporter transgene integrated in the genome for permanent labeling on administration of tamoxifen. Potentially, unexpected effects of tamoxifen (or its active metabolite 4-OH tamoxifen) could disturb the steady state: we have evaluated that the dose used in our experiments does not affect the steady state spermatogenesis (Nakagawa et al. 2007 and data not shown).

Secondly, a more direct method of cell fate analysis is live-imaging. GFP and other fluorescent proteins have enabled visualization of the cells of interest in living organisms when expressed under an appropriate promoter. Thus, filming of living cells' action in living animals became a realistic challenge. In 2007, our group established an in vivo live-imaging system for GFP-labeled spermatogonia in a testis of anesthetized mice (Yoshida et al. 2007). Live imaging is quite informative: entire pedigree of a cell lineage, morphological change and movements, and cell death are only available from this technique. However, prolonged cell fate analyses (for months and sometimes for years) are necessary for the stem cell assessment, which are available only from pulse-chase experiments. So, combination of these complementary strategies is very useful. By these experiments, a number of properties of mouse undifferentiated spermatogonia have been uncovered in recent years (Nakagawa et al. 2007, 2010, Yoshida et al. 2007, Sada et al. 2009).

\section{Stem cells supporting the steady state}

To dissect the mouse spermatogenic stem cell system, pulse-labeling experiments have been applied for Nanos $2^{\text {pos }}$ and Neurog $3^{\text {pos }}$ subpopulations of undifferentiated spermatogonia, using transgenic mice expressing tamoxifen-inducible Cre under the control of Nanos2 and Neurog3 regulatory sequences (Nakagawa et al. 2007, 2010, Sada et al. 2009). Many of the labeled Nanos $2^{\text {pos }}$ spermatogonia persisted in the tissue and continued to produce differentiating progeny for several months, indicating the central role of Nanos2 ${ }^{\text {pos }}$ (also $G$ fra $1^{\text {pos }}$ ) spermatogonia in maintenance of steady state (Sada et al. 2009). On the other hand, a vast majority of the labeled Neurog $3^{\text {pos }}$ spermatogonia proliferated and differentiated but did not stay in the tissue (Nakagawa et al. 2007, 2010). It is also supported that Nanos2 ${ }^{\text {pos} /}$ Gfra $1^{\text {pos }} /$ Neurog $3^{\text {neg }}$ spermatogonia give rise to Neurog $3^{\text {pos }}$ (also Nanos $2^{\text {neg }} /$ Gra $1^{\text {neg }} /$ Nanos $3^{\text {high }}$ ) 

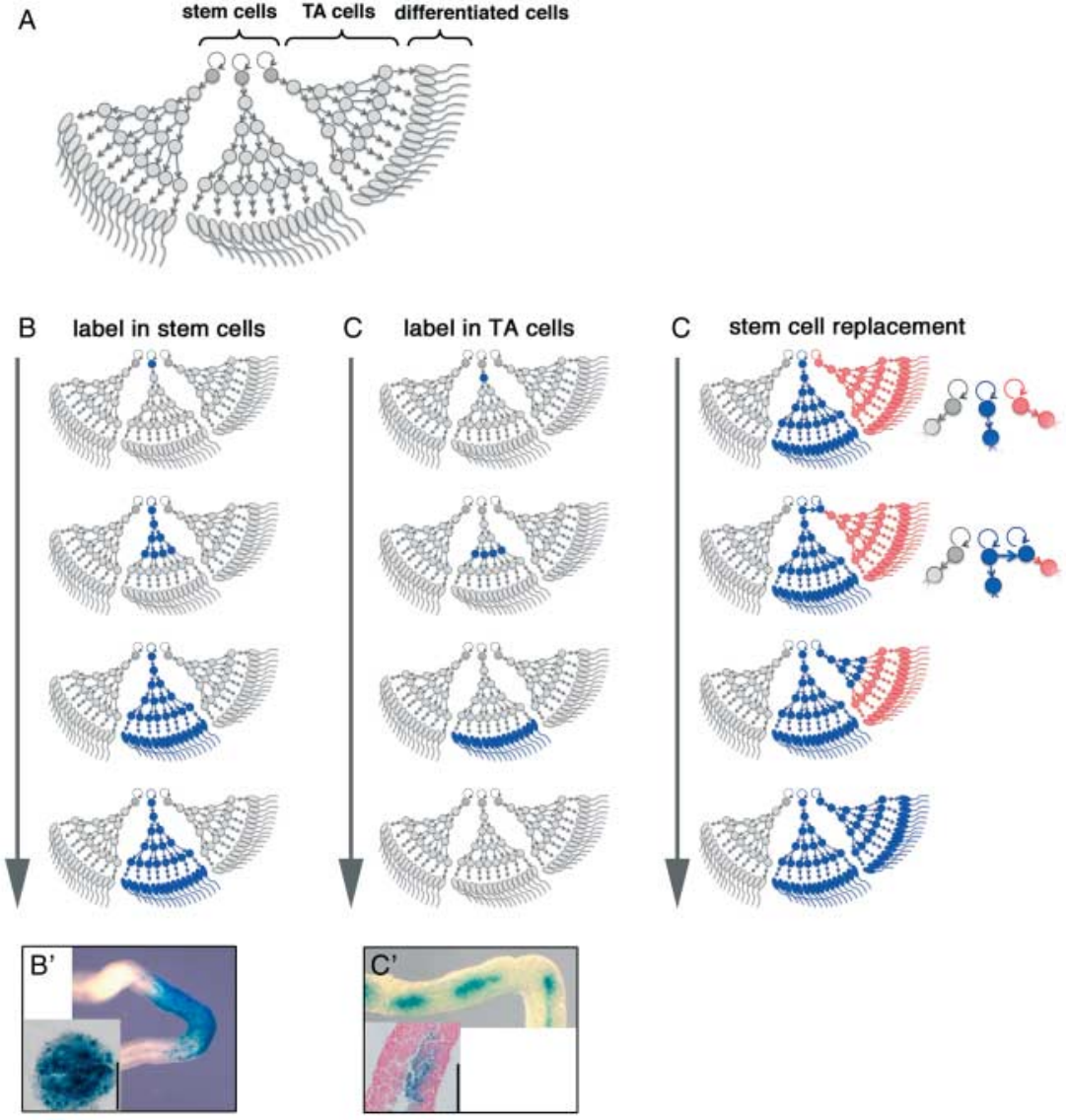

Figure 3 Pulse-chase experiment to dissect the stem cell system. (A) A conceptual stem cell system, which includes self-renewing stem cells, TA (transit-amplifying) cells, and differentiated cells. (B) When a stem cell is pulsed labeled, the labeled descendants will include both selfrenewing and differentiating progeny, so that all the cells in a particular part of the tissue will be continuously labeled. (C) When a TA cell is pulsed, the labeled descendants will proliferate and differentiate but do not persist within the tissue. ( $B^{\prime}$ and $C^{\prime}$ ) Examples of patches derived from pulse-labeled stem $\left(\mathrm{B}^{\prime}\right)$ and TA $\left(\mathrm{C}^{\prime}\right)$ cells in mouse seminiferous tubules. In these cases, cells labeled with Lacz expression were visualized in blue. Insets, cross sections. (D) If stem cells replace with each other, some stem cell cohorts (such that shown in red) will be extinct, while others (such that shown in blue) replenish them and expand their territories. Such a stem cell replacement is actually observed in mouse spermatogenesis (Fig. 4). (B') and (C'). Modified from Nakagawa $T$, Nabeshima $Y$ \& Yoshida $S$ 2007 Functional identification of the actual and potential stem cell compartments in mouse spermatogenesis. Developmental Cell 12 195-206. Reproduced with permission from Elsevier. Copyright 2007 Elsevier. spermatogonia, and that a bulk of Neurog $3^{\text {pos }}$ spermatogonia differentiates into Kit ${ }^{\text {pos }}$ differentiating spermatogonia (Sada et al. 2009, Nakagawa et al. 2010). Altogether, it appears that Gfra $1^{\text {pos } / N a n o s} 2^{\text {pos }}$ spermatogonia mainly self-renew their population and give rise to Neurog $3^{\text {pos }}$ spermatogonia, which in turn mostly act as transient amplifying cells and differentiate into being Kit $^{\text {pos }}$ (Fig. 2C).

Given that the Gfra $1^{\text {pos }} /$ Nanos $2^{\text {pos }}$ and the Neurog $3^{\text {pos }}$ populations largely correspond to $A_{s} / A_{p r}$ and $A_{a l}$ spermatogonia, respectively, this behavioral hierarchy in steady state seems to parallel the morphological hierarchy that appeared in the classic ' $\mathrm{A}_{\mathrm{s}}$ model' (compare Fig. 2A and C). It is noteworthy that live imaging of Neurog $3^{\text {pos }}$ spermatogonia directly observed the extension of spermatogonial syncytia for the first time (e.g. $A_{p r} \rightarrow A_{a l-4} \rightarrow A_{a l-8}$ ), which had long been believed to occur based on the snapshot analyses (Nakagawa et al. 2007, Yoshida et al. 2007).

However, some observations in undisturbed testis were not supposed by the $A_{s}$ model (Fig. 2D). First, contrary to the idea that all the $A_{s}$ are equivalent and act as stem cells, Neurog $3^{\text {pos }}$ subset of $A_{s}$ spermatogonia preferentially differentiated. Secondly, it is shown that a portion of Neurog $3^{\text {pos }}$ cells sometimes 'revert' into being Gra $7^{\text {pos }}$ and act as self-renewing stem cells
(Nakagawa et al. 2007, 2010). Moreover, syncytia of Neurog $3^{\text {pos }}$ spermatogonia occasionally fragmented into single cells and shorter syncytia (Nakagawa et al. 2010). However, it is an important question but still to be determined whether the resultant $A_{s}$ cells after fragmentation of syncytial spermatogonia do replenish the stem cell pool or not.

\section{Regeneration is supported by different population from that acting in steady state}

It is generally considered that a single population of stem cells both supports the cell turnover in steady state and contributes to regeneration after tissue injury or transplantation. However, the lack of adequate experimental systems has prevented researchers from determining whether these cells, both can be designated as 'stem cells', are truly the same.

Nakagawa et al. $(2007,2010)$ analyzed the behavior of pulse-labeled Neurog $3^{\text {pos }}$ spermatogonia population under three different conditions, i.e. steady state, regeneration after insult, and colony formation after transplantation (an extreme case of regeneration). The results suggest that Neurog3 ${ }^{\text {pos }}$ spermatogonia (mostly found in syncytia), which differentiate without selfrenewal in steady state with a high probability, shift 
their mode to self-renewal in response to tissue insult or transplantation. This accompanied increased 'reversion' of Neurog $3^{\text {pos }}$ spermatogonia into being Gfra $7^{\text {pos }}$ (reversion in terms of gene expression): increased fragmentation of syncytia (reversion in terms of morphology) was also expected to occur at a high frequency, but this is yet to be examined experimentally.

On the other hand, behavior of Gfra ${ }^{\text {pos }}$ spermatogonia under regeneration or after transplantation is still to be elucidated. Grisanti et al. (2009) showed that transplantable stem cell activity of Gfra $7^{\text {pos }}$ fraction is not as high as Gfra ${ }^{\text {neg }}$ (probably Neurog3 $3^{\text {pos }}$ ) fraction, suggesting that, unlike steady state, contribution of Gfra $1^{\text {pos }}$ spermatogonia in post-transplantation colony formation would not be so crucial. Systematic analyses of the Gfra $7^{\text {pos }}$ population after transplantation and on regeneration will be warranted to address this important issue.

These data demonstrate that a unique population of 'stem cells' does not play a role in every aspect of stem cell function; rather, different cell populations are recruited into stem cell pools in different contexts. In regeneration, behaviors of the stem cell compartment become largely different from what was proposed by

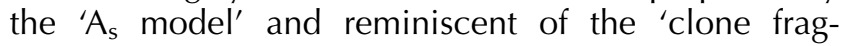
mentation model', which were based on the stem cell behavior during regeneration (Erickson (1976, 1981) and Meistrich \& van Beek (1993) for review). Therefore, the classical ' $\mathrm{A}_{\mathrm{s}}$ model' and 'clone-fragmentation model' appear to represent different aspects of a reversible and flexible stem cell system. Similar reversion, namely fragmentation of syncytial spermatogonia into germline stem cells, has been observed in Drosophila spermatogenesis and oogenesis (Brawley \& Matunis 2004, Kai \& Spradling 2004).

\section{Hierarchy and reversibility of the stem cell compartments}

The above-mentioned evidence clearly indicates that the mouse spermatogenic stem cell compartment includes heterogeneous cell types with different degrees of stem cell potential (i.e. probability of self-renewal vs differentiation), rather than a small population of a single kind of stem cells. Interestingly, these different cell populations are recruited to the stem cell pool in different situations, which may be beneficial for tissue homeostasis in that the stem cell pool can be recovered quickly when necessary.

The spermatogenic stem cell system involves at least two types of heterogeneity: morphology (number of connected cells within a syncytium) and gene expression (Gfra ${ }^{\text {pos }} /$ Nanos $^{\text {pos }}$ and Neurog $3^{\text {pos }}$ populations). These two features are related to each other - the longer the syncytia are, the higher the proportion of Neurog $3^{\text {pos }}$ cells is - but they are not perfectly matched (Fig. 2A).
Of note, both differentiation-related traits can be reversible. Then, which feature is more closely related to the regulation of cellular function, morphology, or gene expression? Data suggest that the gene expression shows a more close relationship with differentiation: in steady state, Neurog $3^{\text {pos }}$ spermatogonia are clearly directed for differentiation regardless of their morphology (even $A_{s}$ spermatogonia that are Neurog $3^{\text {pos }}$ are destined for differentiation), and Gfra $7^{\text {pos }}$ cells barely become differentiating spermatogonia directly (Nakagawa et al. 2010). Neurog $3^{\text {pos }}$ spermatogonia represent a unique property: while they are destined for differentiation, they clearly retain their potential of self-renewal. This is consistent with the idea of 'potential stem cells' that was conceptually proposed by Potten \& Loeffler (1990).

On the other hand, it is no doubt that syncytium formation, which is a characteristic for germ cells widely in animal kingdom (Pepling et al. 1999), is an important property associated with differentiation. The relationship between morphology and gene expression in the stem cell self-renewal and differentiation is one of the important questions for the complete understanding of the stem cell system. With this regard, elucidation of the live behaviors of Gfra $7^{\text {pos }}$ population will be very much warranted.

\section{Stem cell replacement in steady state}

From a classical viewpoint, every single stem cell is supposed to strictly repeat asymmetric division to form one self-renewing and one differentiating daughters, and it is carefully protected in tissue as schematically shown in Fig. 4A. The Drosophila gonads have been representing such a typical stem cell system and have provided a theoretical basis widely for stem cell research (Fuller \& Spradling 2007, Losick et al. 2011, Spradling et al. 2011). On the other hand, investigation has been warranted for other systems including mammalian spermatogenesis.

A study of pulse chase of individual mouse spermatogenic stem cell-derived cohorts over 1 year gave unexpected results (Nakagawa et al. 2007). If you assume the above-mentioned scenario of repeated asymmetric division, all the individual stem cell lineages are expected to persist over time and their size should be constant (Fig. 4A). In reality, however, a majority of stem cell lineages that had persisted over, for example, 3 months became extinct in the following months (Fig. 4B), while the surviving lineages expanded (Fig. 4C). This indicates that stem cells regularly lose their function (perhaps due to differentiation of all the descendants) and are replenished by stem cells that were born from neighboring stem cell cohorts (Figs 3D and 4D). Therefore, although spermatogenesis is a highly stable process, its stem cells are continuously turning over with each other. Mathematical analyses suggested 

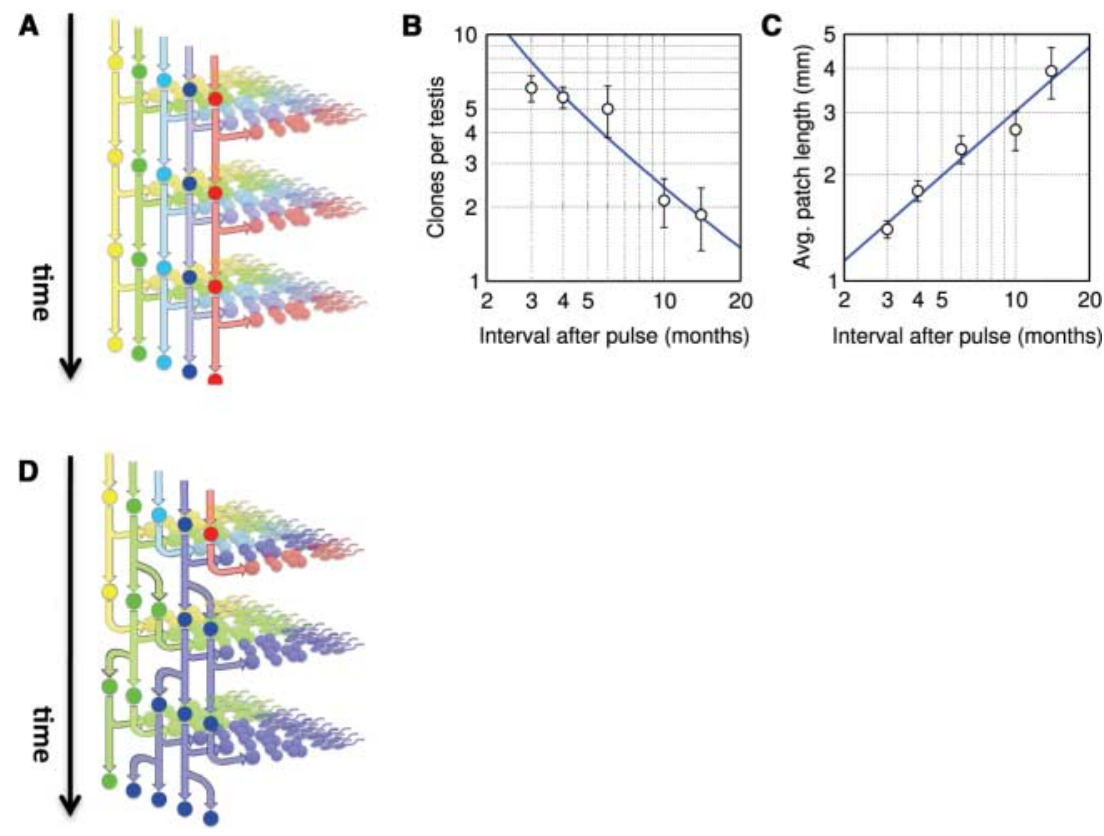

Figure 4 Stem cell replacement in steady-state spermatogenesis. (A) Conceptual illustration of stem cell fate based on the assumption that stem cells always undergo strict asymmetric division and never replace with each other. Lineage of initial stem cells should be stable over time (five stem cell lineages are shown in different colors). (B and C) Chase of labeled single stem cell-derived patches in seminiferous tubules: many of the stem cell lineages become extinct (B) while others expand (C) over months. Reproduced from Klein AM, Nakagawa T, Ichikawa R, Yoshida S \& Simons BD 2010 Mouse germ line stem cells undergo rapid and stochastic turnover. Cell Stem Cell 7 214-224. Reproduced with permission from Elsevier. Copyright 2010 Elsevier. (D) Scheme for stem cell replacement that explains the actual pulse-chase data shown in (B) and (C).

that stem cells have an average longevity of $<2$ weeks and that such a frequent replacement occurs stochastically (Klein et al. 2010). The stochastic features of stem cell replacement obtained from this macroscopic lineage tracing may suggest that the behavior of individual stem cells is equipotent regardless of whether they are 'bona fide', 'copied', or 'reverted' stem cells. However, this does not mean that individual stem cells are completely the same and behave independently from their microscopic history and local situations. It is one of the most interesting and the biggest challenges to link such macroscopic scale of population dynamics of stem cells with microscopic scale of behaviors of individual spermatogonia.

\section{Flexibility and stochasticity may be common features of stem cells}

The above-mentioned findings may shift our view for the mouse spermatogenic stem cells. 'Stem cells' may not be a rare entity of specialized cells that always undergoes asymmetric division, but may be a population of cells showing flexible and stochastic features. Similar characteristics are recently emerging from other stem cell systems, too. The behavior of pulse-labeled stem cells in mammalian skin and intestinal epithelia revealed essentially the same class of mathematical signatures, suggesting that stochasticity commonly underlies the stem cell systems (Clayton et al. 2007, Doupe et al. 2010,
Lopez-Garcia et al. 2010, Snippert et al. 2010, Klein \& Simons 2011, Simons \& Clevers 2011).

Interestingly, similar flexible stem cell behavior is also suggested in Drosophila germline stem cells, which was classically considered as a 'stereotypic' system. Drosophila spermatogenic stem cells turn over with age, which was shown by pulse-chase experiment (Wallenfang et al. 2006). In addition, recent success of long-term live imaging of testis organ culture visualized interesting behaviors of stem cell daughters (Sheng \& Matunis 2011): although a stem cell always divided in a geographically asymmetric manner, namely perpendicular to the niche (hub), as had been observed (Yamashita \& Fuller 2005, Losick et al. 2011, Spradling et al. 2011), the subsequent fates of daughter cells were not always asymmetric. According to Sheng and Matunis (2011), $\sim 7$ and $\sim 13 \%$ of stem cell divisions produced daughter pairs that both self-renew (symmetric renewal) and daughter pairs that both differentiate (symmetric differentiation) respectively. The probabilities of symmetric renewal and symmetric differentiation were increased and decreased, respectively, and the reversion from syncytia also takes place when regeneration was induced. These altogether result in the recovery of stem cell pool after tissue insult. It may be an issue of semantics whether this stem cell replacement is an exceptional event or whether it represents regular turnover. The observed frequency looks high enough to support the latter, although the possibility of 
an artifact caused by ex vivo cultivation needs to be assessed carefully. I think that mathematical analysis of pulse-labeled stem cell cohorts in vivo is warranted in this system as well.

\section{Remaining questions: spatio-temporal regulation of the stem cells}

Stem cells' behavior is regulated properly in the seminiferous tubules. Stem cell niche, which is generally defined as the microenvironment that regulates stem cell function, is considered as an indispensable element of the stem cell system (Morrison \& Spradling 2008). Mouse seminiferous tubules do not represent clearly specialized niche structure cells unlike Drosophila testes (hub cells) and ovaries (cap cells), or mouse intestine (base of the crypts). This is why the study of the mouse spermatogenic stem cell niche has been based on the localization of $\mathrm{A}_{\text {undiff }}$ spermatogonia. Thanks to precise and insightful observations of testis sections, Chiarini-Garcia et al. discovered that these $A_{\text {undiff }}$ spermatogonia preferentially localize to the area adjacent to the interstitium between seminiferous tubules (Chiarini-Garcia et al. 2001, 2003). Subsequently, three-dimensional reconstruction of serial sections of the tubules confirmed this biased localization of $A_{\text {undiff }}$ spermatogonia to the blood vessels and accompanying interstitial cells (Yoshida et al. 2007). In addition, live imaging visualized that when Neurog $3^{\text {pos }}$ spermatogonia transit into $A_{1}$ spermatogonia they depart this presumptive vasculature-associated niche region and spread to all over the basal compartment (Yoshida et al. 2007). These region-related distributions and movements of spermatogonia clearly indicate that seminiferous tubules, although seemingly uniform, comprised multiple functional compartments in a manner related to the vasculature pattern. In addition, alteration of vasculature pattern accompanies the reorganization of spermatogonia, suggesting that the blood vessels (and/or their associated cells) determine the niche region. Given that blood vessels and interstitial cells do not have direct contact with spermatogonia, some molecular mechanisms should link the vasculature/interstitium with the niche microenvironment that is proximal to the stem cells (Yoshida 2011). One of such molecules may be Csf1, which are expressed in interstitial cells and a subset of peritubular cells and increase the colony-formation activity in cultured spermatogonia (Oatley et al. 2009). However, the molecular and cellular nature of this specialized microenvironment remains to be mostly elucidated.

Another unsolved question is related to the seminiferous epithelial cycle: differentiation process from $A_{1}$ spermatogonia to mature sperm, which takes place 35 days, progresses in a periodical manner with the interval of 8.6 days. Sertoli cells also change their functions cyclically so that they can support the different stages of germ cells properly (Oakberg 1956, Russell et al. 1990). The stem cell behaviors seem to be also related to this cyclic phenomenon (de Rooij 1998), suggesting that some cycle-related environmental cues regulate the undifferentiated spermatogonia. Of note, expression of GDNF, the ligand for Gfra1, shows an oscillating pattern along with the seminiferous epithelial cycle (Johnston et al. 2011, Sato et al. 2011, Grasso et al. 2012). It is also suggested that local retinoic acid concentration oscillates along with the cycle and induce transition from 'undifferentiated' to $A_{1}$ differentiating spermatogonia at stages VII and VIII (Sugimoto et al. 2012). In addition, retinoic acid also acts on Sertoli cells so that germ cell differentiation and Sertoli cells are well coordinated. Elucidation of the role of these and other cycle-related environmental factors on the stem cell regulation remains as an open question.

\section{Declaration of interest}

The authors declare that there is no conflict of interest that could be perceived as prejudicing the impartiality of the research reported.

\section{Funding}

The work of our research group described in this review was partly supported by grant-in-aid for scientific research (KAKENHI) on innovative areas, 'Regulatory Mechanism of Gamete Stem Cells' from MEXT, Japan.

\section{Acknowledgements}

I am grateful to all our group members of Division of Germ Cell Biology, National Institute for Basic Biology and Department of Pathology and Tumor Biology, Faculty of Medicine, Kyoto University. Insightful discussions with Robert Braun, Benjamin Simons, Satoru Kobayashi, Takehiko Ogawa, and other collaborators are appreciated. I also thank Margaret Fuller for her clear suggestion of the terminology for spermatogonial syncytia.

\section{References}

Barroca V, Lassalle B, Coureuil M, Louis JP, Le Page F, Testart J, Allemand I, Riou L \& Fouchet P 2009 Mouse differentiating spermatogonia can generate germinal stem cells in vivo. Nature Cell Biology 11 190-196. (doi:10.1038/ncb1826)

Brawley C \& Matunis E 2004 Regeneration of male germline stem cells by spermatogonial dedifferentiation in vivo. Science 304 1331-1334. (doi:10.1126/science.1097676)

Brinster RL \& Avarbock MR 1994 Germline transmission of donor haplotype following spermatogonial transplantation. PNAS 91 11303-11307. (doi:10.1073/pnas.91.24.11303)

Brinster RL \& Zimmermann JW 1994 Spermatogenesis following male germ-cell transplantation. PNAS 91 11298-11302. (doi:10.1073/pnas. 91.24.11298)

Buaas FW, Kirsh AL, Sharma M, McLean DJ, Morris JL, Griswold MD, de Rooij DG \& Braun RE 2004 Plzf is required in adult male germ cells for stem cell self-renewal. Nature Genetics 36 647-652. 
Buckingham ME \& Meilhac SM 2011 Tracing cells for tracking cell lineage and clonal behavior. Developmental Cell 21 394-409. (doi:10.1016/j. devcel.2011.07.019)

Chiarini-Garcia H \& Russell LD 2001 High-resolution light microscopic characterization of mouse spermatogonia. Biology of Reproduction $\mathbf{6 5}$ 1170-1178. (doi:10.1095/biolreprod65.4.1170)

Chiarini-Garcia H \& Russell LD 2002 Characterization of mouse spermatogonia by transmission electron microscopy. Reproduction 123 567-577. (doi:10.1530/rep.0.1230567)

Chiarini-Garcia H, Hornick JR, Griswold MD \& Russell LD 2001 Distribution of type A spermatogonia in the mouse is not random. Biology of Reproduction 65 1179-1185. (doi:10.1095/biolreprod65.4. 1179)

Chiarini-Garcia H, Raymer AM \& Russell LD 2003 Non-random distribution of spermatogonia in rats: evidence of niches in the seminiferous tubules. Reproduction 126 669-680. (doi:10.1530/rep.0. 1260669)

Clayton E, Doupe DP, Klein AM, Winton DJ, Simons BD \& Jones PH 2007 A single type of progenitor cell maintains normal epidermis. Nature $\mathbf{4 4 6}$ 185-189. (doi:10.1038/nature05574)

Clermont Y \& Bustos-Obregon E 1968 Re-examination of spermatogonial renewal in the rat by means of seminiferous tubules mounted "in toto". American Journal of Anatomy 122 237-247. (doi:10.1002/aja. 1001220205)

Costoya JA, Hobbs RM, Barna M, Cattoretti G, Manova K, Sukhwani M, Orwig KE, Wolgemuth DJ \& Pandolfi PP 2004 Essential role of Plzf in maintenance of spermatogonial stem cells. Nature Genetics 36 653-659.

Doupe DP, Klein AM, Simons BD \& Jones PH 2010 The ordered architecture of murine ear epidermis is maintained by progenitor cells with random fate. Developmental Cell 18 317-323. (doi:10.1016/j.devcel.2009. 12.016)

Erickson BH 1976 Effect of 60Co gamma radiation on the stem and differentiating spermatogonia of the postpubertal rat. Radiation Research 68 433-448. (doi:10.2307/3574325)

Erickson BH 1978 Effect of continuous gamma-radiation on the stem and differentiating spermatogonia of the adult rat. Mutation Research $\mathbf{5 2}$ 117-128. (doi:10.1016/0027-5107(78)90100-8)

Erickson BH 1981 Survival and renewal of murine stem spermatogonia following 60Co gamma radiation. Radiation Research 86 34-51. (doi:10.2307/3575597)

Fox DT, Morris LX, Nystul T \& Spradling AC 2008 Lineage analysis of stem cells. In StemBook, edn 2010/07/09. Cambridge (MA): Harvard Stem Cell Institute.

Fuller MT \& Spradling AC 2007 Male and female Drosophila germline stem cells: two versions of immortality. Science 316 402-404. (doi:10.1126/ science.1140861)

Grasso M, Fuso A, Dovere L, de Rooij DG, Stefanini M, Boitani C \& Vicini E 2012 Distribution of GFRA1-expressing spermatogonia in adult mouse testis. Reproduction 143 325-332. (doi:10.1530/REP-11-0385)

Grisanti L, Falciatori I, Grasso M, Dovere L, Fera S, Muciaccia B, Fuso A, Berno V, Boitani C, Stefanini M et al. 2009 Identification of spermatogonial stem cell subsets by morphological analysis and prospective isolation. Stem Cells 27 3043-3052.

Hofmann MC, Braydich-Stolle L, Dettin L, Johnson E \& Dym M 2005a Immortalization of mouse germ line stem cells. Stem Cells 23 200-210. (doi:10.1634/stemcells.2003-0036)

Hofmann MC, Braydich-Stolle L \& Dym M 2005b Isolation of male germline stem cells; influence of GDNF. Developmental Biology 279 114-124. (doi:10.1016/j.ydbio.2004.12.006)

Hogarth CA \& Griswold MD 2010 The key role of vitamin A in spermatogenesis. Journal of Clinical Investigation 120 956-962. (doi:10.1172/JCl41303)

Huckins C 1971 The spermatogonial stem cell population in adult rats. I. Their morphology, proliferation and maturation. Anatomical Record 169 533-557. (doi:10.1002/ar.1091690306)

Johnston DS, Olivas E, DiCandeloro P \& Wright WW 2011 Stage-specific changes in GDNF expression by rat Sertoli cells: a possible regulator of the replication and differentiation of stem spermatogonia. Biology of Reproduction 85 763-769. (doi:10.1095/biolreprod.110.087676)

Kai T \& Spradling A 2004 Differentiating germ cells can revert into functional stem cells in Drosophila melanogaster ovaries. Nature $\mathbf{4 2 8}$ 564-569. (doi:10.1038/nature02436)
Kanatsu-Shinohara M, Ogonuki N, Inoue K, Miki H, Ogura A, Toyokuni S \& Shinohara T 2003 Long-term proliferation in culture and germline transmission of mouse male germline stem cells. Biology of Reproduction 69 612-616. (doi:10.1095/biolreprod.103.017012)

Klein AM \& Simons BD 2011 Universal patterns of stem cell fate in cycling adult tissues. Development 138 3103-3111. (doi:10.1242/dev.060103)

Klein AM, Nakagawa T, Ichikawa R, Yoshida S \& Simons BD 2010 Mouse germ line stem cells undergo rapid and stochastic turnover. Cell Stem Cell 7 214-224. (doi:10.1016/j.stem.2010.05.017)

Kubota H, Avarbock MR \& Brinster RL 2004 Growth factors essential for self-renewal and expansion of mouse spermatogonial stem cells. PNAS 101 16489-16494. (doi:10.1073/pnas.0407063101)

Lopez-Garcia C, Klein AM, Simons BD \& Winton DJ 2010 Intestinal stem cell replacement follows a pattern of neutral drift. Science 330 822-825. (doi:10.1126/science.1196236)

Losick VP, Morris LX, Fox DT \& Spradling A 2011 Drosophila stem cell niches: a decade of discovery suggests a unified view of stem cell regulation. Developmental Cell 21 159-171. (doi:10.1016/j.devcel. 2011.06.018)

Meistrich ML \& van Beek ME 1993 Spermatogonial stem cells. In Cell and Molecular Biology of the Testis, pp 266-295. Eds C Desjardins\& LL Ewing. New York, NY: Oxford University Press.

Morrison SJ \& Spradling AC 2008 Stem cells and niches: mechanisms that promote stem cell maintenance throughout life. Cell 132 598-611. (doi:10.1016/j.cell.2008.01.038)

Nakagawa T, Nabeshima Y \& Yoshida S 2007 Functional identification of the actual and potential stem cell compartments in mouse spermatogenesis. Developmental Cell 12 195-206. (doi:10.1016/j. devcel.2007.01.002)

Nakagawa T, Sharma M, Nabeshima Y, Braun RE \& Yoshida S 2010 Functional hierarchy and reversibility within the murine spermatogenic stem cell compartment. Science 328 62-67. (doi:10.1126/science. 1182868)

Nishimune Y, Aizawa S \& Komatsu T 1978 Testicular germ cell differentiation in vivo. Fertility and Sterility 29 95-102.

Oakberg EF 1956 A description of spermiogenesis in the mouse and its use in analysis of the cycle of the seminiferous epithelium and germ cell renewal. American Journal of Anatomy 99 391-413. (doi:10.1002/aja. 1000990303)

Oakberg EF 1971 Spermatogonial stem-cell renewal in the mouse. Anatomical Record 169 515-531. (doi:10.1002/ar.1091690305)

Oatley JM, Oatley MJ, Avarbock MR, Tobias JW \& Brinster RL 2009 Colony stimulating factor 1 is an extrinsic stimulator of mouse spermatogonial stem cell self-renewal. Development 136 1191-1199. (doi:10.1242/dev. 032243)

Oatley MJ, Kaucher AV, Racicot KE \& Oatley JM 2011 Inhibitor of DNA binding 4 is expressed selectively by single spermatogonia in the male germline and regulates the self-renewal of spermatogonial stem cells in mice. Biology of Reproduction 85 347-356. (doi:10.1095/biolreprod. 111.091330)

Ohbo K, Yoshida S, Ohmura M, Ohneda O, Ogawa T, Tsuchiya H, Kuwana T, Kehler J, Abe K, Scholer HR et al. 2003 Identification and characterization of stem cells in prepubertal spermatogenesis in mice. Developmental Biology 258 209-225. (doi:10.1016/S00121606(03)00111-8)

van Pelt AM \& de Rooij DG 1990 Synchronization of the seminiferous epithelium after vitamin A replacement in vitamin A-deficient mice. Biology of Reproduction 43 363-367. (doi:10.1095/biolreprod43.3.363)

Pepling ME, de Cuevas M \& Spradling AC 1999 Germline cysts: a conserved phase of germ cell development? Trends in Cell Biology 9 257-262. (doi:10.1016/S0962-8924(99)01594-9)

Potten CS \& Loeffler M 1990 Stem cells: attributes, cycles, spirals, pitfalls and uncertainties. Lessons for and from the crypt. Development $\mathbf{1 1 0}$ 1001-1020.

de Rooij DG 1998 Stem cells in the testis. International Journal of Experimental Pathology 79 67-80. (doi:10.1046/j.1365-2613.1998. 00057.x)

de Rooij DG \& Russell LD 2000 All you wanted to know about spermatogonia but were afraid to ask. Journal of Andrology 21 776-798.

Russell L, Ettlin R, Sinha Hikim A \& Clegg E 1990 Histological and histopathological evaluation of the testis. Clearwater, FI: Cache River Press. 
Sada A, Suzuki A, Suzuki H \& Saga Y 2009 The RNA-binding protein NANOS2 is required to maintain murine spermatogonial stem cells. Science 325 1394-1398. (doi:10.1126/science.1172645)

Sato T, Aiyama Y, Ishii-Inagaki M, Hara K, Tsunekawa N, Harikae K, Uemura-Kamata M, Shinomura M, Zhu XB, Maeda S et al. 2011 Cyclical and patch-like GDNF distribution along the basal surface of Sertoli cells in mouse and hamster testes. PLOS ONE 6 e28367. (doi:10.1371/journal. pone.0028367)

Schrans-Stassen BH, van de Kant HJ, de Rooij DG \& van Pelt AM 1999 Differential expression of c-kit in mouse undifferentiated and differentiating type A spermatogonia. Endocrinology 140 5894-5900. (doi:10.1210/ en.140.12.5894)

Sheng XR \& Matunis E 2011 Live imaging of the Drosophila spermatogonial stem cell niche reveals novel mechanisms regulating germline stem cell output. Development 138 3367-3376. (doi:10.1242/dev.065797)

Shinohara T, Orwig KE, Avarbock MR \& Brinster RL 2000 Spermatogonial stem cell enrichment by multiparameter selection of mouse testis cells. PNAS 97 8346-8351. (doi:10.1073/pnas.97.15.8346)

Shinohara T, Orwig KE, Avarbock MR \& Brinster RL 2001 Remodeling of the postnatal mouse testis is accompanied by dramatic changes in stem cell number and niche accessibility. PNAS 98 6186-6191. (doi:10.1073/ pnas.111158198)

Simons BD \& Clevers H 2011 Strategies for homeostatic stem cell self-renewal in adult tissues. Cell 145 851-862. (doi:10.1016/j.cell. 2011.05.033)

Snippert HJ, van der Flier LG, Sato T, van Es JH, van den Born $M$, Kroon-Veenboer C, Barker N, Klein AM, van Rheenen J, Simons BD et al. 2010 Intestinal crypt homeostasis results from neutral competition between symmetrically dividing Lgr5 stem cells. Cell 143 134-144. (doi:10.1016/j.cell.2010.09.016)

Spradling A, Fuller MT, Braun RE \& Yoshida S 2011 Germline stem cells. Cold Spring Harbor Perspectives in Biology 3 a002642. (doi:10.1101/ cshperspect.a002642)

Sugimoto R, Nabeshima Y \& Yoshida S 2012 Retinoic acid metabolism links the periodical differentiation of germ cells with the cycle of Sertoli cells in mouse seminiferous epithelium. Mechanisms of Development 128 610-624. (doi:10.1016/j.mod.2011.12.003)

Suzuki H, Sada A, Yoshida S \& Saga Y 2009 The heterogeneity of spermatogonia is revealed by their topology and expression of marker proteins including the germ cell-specific proteins Nanos2 and Nanos3. Developmental Biology 336 222-231. (doi:10.1016/j.ydbio.2009.10. 002)

Tokuda M, Kadokawa Y, Kurahashi H \& Marunouchi T 2007 CDH1 is a specific marker for undifferentiated spermatogonia in mouse testes. Biology of Reproduction 76 130-141. (doi:10.1095/biolreprod.106. 053181)

Wallenfang MR, Nayak R \& DiNardo S 2006 Dynamics of the male germline stem cell population during aging of Drosophila melanogaster. Aging Cell 5 297-304. (doi:10.1111/j.1474-9726.2006.00221.x)

Yamashita YM \& Fuller MT 2005 Asymmetric stem cell division and function of the niche in the Drosophila male germ line. International Journal of Hematology 82 377-380. (doi:10.1532/IJH97.05097)

Yoshida S 2010 Stem cells in mammalian spermatogenesis. Development, Growth \& Differentiation 52 311-317. (doi:10.1111/j.1440-169X.2010. 01174.x)

Yoshida S 2011 Stem cell niche system in mouse spermatogenesis. In Male Germline Stem Cells: Developmental and Regenerative Potential, Stem cell biology and regenerative medicine series, pp 159-175. Humana Press.

Yoshida S, Takakura A, Ohbo K, Abe K, Wakabayashi J, Yamamoto M, Suda T \& Nabeshima Y 2004 Neurogenin3 delineates the earliest stages of spermatogenesis in the mouse testis. Developmental Biology 269 447-458. (doi:10.1016/j.ydbio.2004.01.036)

Yoshida S, Sukeno M \& Nabeshima Y 2007 A vasculature-associated niche for undifferentiated spermatogonia in the mouse testis. Science 317 1722-1726. (doi:10.1126/science.1144885)

Zheng K, Wu X, Kaestner KH \& Wang PJ 2009 The pluripotency factor LIN28 marks undifferentiated spermatogonia in mouse. BMC Developmental Biology 9 38. (doi:10.1186/1471-213X-9-38)

Received 28 August 2011

First decision 4 October 2011

Revised manuscript received 10 June 2012

Accepted 25 June 2012 